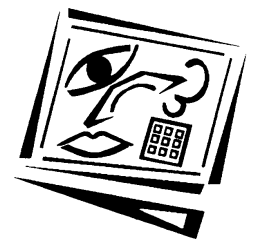

\title{
Integrating book, digital content and robot for enhancing elementary school students' learning of English
}

\author{
Nian-Shing Chen, Benazir Quadir and Daniel C. Teng \\ National Sun Yat-sen University, Taiwan
}

\begin{abstract}
Early school years are an important period to lay out the foundation for learning a second language. In addition to mastering the basic language skills and keeping the learning process fun, promoting a lifelong learning habit should also be emphasised. Motivating elementary school students to learn English and avoiding misconceptions associated with the learning process are very important issues. This study attempted to explore the integration of book, computer and robot to create a novel and joyful English learning environment. Books are the most common learning media. If we can design a special mechanism linking books with digital learning content and a robot, students will be able to obtain supplementary learning content including motions performed by the robot to enhance learning outcomes. To implement this idea, a new learning system was designed and developed. Learning activities included vocabulary, single sentence read-along, full article read-along, conversation, singalong and dancing. Cloze tests were implemented and the feasibility of the learning system was evaluated. Data collected from field observation and interviews were analysed. The results suggest that this system did enrich students' learning experience and enhance their motivation and engagement.
\end{abstract}

\section{Introduction}

Power (2005) in a Newsweek article issued on 7 March 2005 mentioned that over the next decade there will be two billion people worldwide learning English, and half of the world - accounting for three billion people - will speak English. Being able to communicate in English will be beneficial to adapting oneself to the international society. Many non-English speaking countries regard English as the first foreign language and are committed to improving students' fluency in English (Liu, 2009). Taiwan, for example, set up a new guideline for bilingual education in 2004 to involve students as young as third graders in English learning curriculum (Ministry of Education, 2004).

It is important to motivate young students to learn English while keeping the learning process joyful and enjoyable to gain positive language learning experiences. Developmental social psychology (Erikson, 1963) suggests that human development consists of eight stages, with each stage corresponding to developmental outcomes and strengths. Erikson suggested that failure in one stage will cumulate and hinder the development of the stage that follows. Positive experiences in achieving the stage outcome serves as a foundation for later development, whereas negative experiences resulted from encountering challenges in a particular stage will undermine subsequent development. 
We considered integrating book, computer and robot to create an English learning environment. Books are the most common learning medium. Integrating digital learning content and robot into conventional usage of books may enrich the representation of plain text with multimedia and motions which together may enhance student learning (Chen, Teng, Lee \& Kinshuk, 2011; Wei, Hung, Lee \& Chen, 2011). A lifelike robot provides a way to reify abstract concepts to foster deeper understanding (Mitnik, Recabarren, Nussbaum \& Soto, 2009; You, Shen, Chang, Liu \& Chen, 2006; Wei et al., 2011; Zhang, Kinshuk, Jormannainen \& Sutinen, 2008). To be able to take full advantages of different learning resources, a well-designed integration of books, digital learning content, and the robots is necessary.

\section{Technology-enhanced language learning}

A language itself comprises a complex scheme with multiple interrelated components. Vocabulary, grammar, and pronunciation (sounds) are three basic components of a language (Grauberg, 1997). Learning a language requires one to have knowledge of these three components in a language scheme, knowledge of how they are used, and knowledge of how the three components can be orchestrated for reception (understanding a received input) and expression (producing an output) (Berninger \& Richards, 2002; Grauberg, 1997). In practice, listening, reading, speaking, and writing are four skills rendering these three components in reception and expression; the former two are receptive skills for understanding, and the latter two productive skills for expression. These four skills of learning a language should be equally emphasised.

Language representation can be distinguished into four levels according to its complexity (Berninger \& Richards, 2002; Sakai, 2005), ranging from subword (e.g., phonemes, morphemes), word (e.g., semantics, morphology), clause (e.g., syntax/grammar), and up to discourse/text (e.g., conversation). Language learning starts with lower-level representations such as words, then to higher-level representations such as sentences and discourse, in both the receptive and expressive forms. This study adopted the above mentioned concepts and theories in the designs of the learning activities for the system we developed.

Computer technologies have been used in language learning since the 1960s. Warschauer (1996) suggested that the computer can serve in language learning as a tutor, a stimulus, or a tool for possible learning benefits such as multimodal practice with feedback, individualisation, collaboration, fun factors, and integration of a variety of resources (Warschauer \& Healey, 1998). A technology-enhanced environment for language learning is capable of offering enhanced input, interaction, and linguistic output to learners (Chapelle, 2009). The enhanced input for language learning refers to its versatile manifestation of the content (what linguistic information to be shown) and form (how the information can be shown). The interactivity provided by the computer system can result in an interaction between learner and learner, learner and computer, or within the learner's mind. The linguistic output refers to the oral and written form of language production. Chapelle (2009) suggested that all three features of computerassisted language learning should be considered and integrated in the learning activities.

There have been a considerable number of studies investigating how computer technology may benefit students' language learning. Laufer and Hill (2000), for example, designed a computer-assisted language learning dictionary incorporating multiple lexical information (i.e., explanation in English, translation into first language, 
sound, root, and other information) for EFL students in Hong Kong and Israel. They analysed students' log files of accessing lexical information, and found that different people have different lookup preferences, and that the use of multiple lexical information in the dictionary seemed to reinforce retention. Likewise, Klassen and Milton (1999) found that a multimedia-enhanced learning mode improves students' listening skills. Akbulut (2007) found that students learning vocabulary with associated pictures or videos performed better in the vocabulary test than those who learned only with textual definition (Akbulut, 2007). Similarly, in Chun and Plass' (1996) study, a higher rate of incidental learning was found in students who learned words annotated with text and pictures than those with text and video or text only. Also, they found a correlation between looking up a certain annotation type and using that type as a retrieval cue for remembering words. This finding is consistent with earlier studies of the redundancy effect in brain literacy (Berninger \& Richards, 2002) and multimedia learning (Mayer, 2001; Mayer \& Moreno, 2003), that multiple ways of representing information and procedures is a general principle in brain organisation. Students who were able to form redundant connections tend to be better readers (Berninger, 1994).

An emergent robot technology brings a new kind of knowledge representation. The robot can provide motions and also the social cues in the learning context as in humanto-human conversations (Atkinson, Mayer \& Merrill, 2005; Heerink, Kröse, Wielinga \& Evers, 2008). The use of a robot may increase the authenticity of tasks given to students for problem solving (Chang, Lee, Wang \& Chen, 2010). Mitnik et al. (2009) applied robots in learning kinematics concepts, as well as relevant graph construction and interpretation. They found that students learning with the robot outperformed their counterparts in graph interpretation, and if compared with a similar computersimulated activity, learning with robots was even more effective. Simiarly, Wei et al. (2011) applied robots (made from Lego Mindstorm) in teaching third-graders multiplication and found that the robot motivated student learning and the humanrobot interaction may contribute to student learning outcomes. Though robotic technology has been exploited in a few educational settings, little effort has been attempted to apply it in the context of English learning.

\section{Integrating book, computer, and robot in language learning}

There are difficulties in learning English in non-English-speaking contexts. First, much of the content material is de-contextualised from its daily use. Students learn vocabularies, syntaxes, and grammars without knowing when and how to use them. Samaras and Gismondi (1998) suggested that learning takes place in the continual interactions with the surrounding environment. To help students learn English, therefore, one should consider delivering the instruction in a real context. Second, computer-assisted learning systems may lack enough interactivity to help motivate students to actively participate in the learning activities. Chang, Chan and Yang (2007) suggested that a learning system with high interactivity benefits students' reading performance. Also, a learner-oriented instructional design will motivate students to learn with the computer system (Mitsoni, 2006). Third, as Liu (2000) noticed, learners often have insufficient practice in spoken English after class, which results in a situation where students are not confident in speaking English. Part of the reason is that students were not motivated to use English language after class. A computerassisted learning system, thus, should be able to engage students in practicing their oral English in the real context simulated by the computer system. 
Considering all of the above issues, an effective English learning environment should be able to motivate students to actively participate in learning activities (Coller \& Shernoff, 2009; Coller \& Scott, 2009) and to enhance their engagement in learning (Kebritchi \& Hirumi, 2008). Both verbal and pictorial representations can be used in learning materials to foster students' understanding (Chen \& Chung, 2008).

In this present study, a humanoid robot was employed due to its high versatility in enhancing cognitive and social interactions (Billard, 2003; Birk, Poppinga \& Pfingsthorn, 2009; Pierris \& Lagoudakis, 2009). An English learning environment integrated with book, computer and robot was proposed to deliver textual content, multimedia, and motions all at the same time in an interactive fashion. Students may benefit from the presented multimodal information, as well as social cues, from the system to help them learn. The purpose of this study was, therefore, to (1) design and implement the integration of book, computer, and robot in a learning environment and (2) evaluate the usability and feasibility of the proposed system in English learning practices. We address below the notion of system design, learning activity design, and implementation of the learning system, followed by the system evaluation. We discuss relevant issues found in this study and provide suggestions for future research.

\section{Methodology}

\section{System design and implementation}

The conceptual framework for the integration of book, computer, and robot is depicted in Figure 1. The student is an actor in this integrated learning environment. Following the content of the book, the student is able to perceive the written form of English in the book, but also the form of multimedia in the computer and that of motions from the robot and have interactions with the computer and/or the robot. The computer was used to store relevant multimedia resources locally or to access directly from the Internet and display them according to the input from the book. The robot was designed specifically to perform motions interactively in response to the book content and audio input from the student. Encodings were used to connect to the book, computer and robot together. These three learning resources together created an environment for learning English which can be fun and enjoyable for students.

Radio-frequency identification (RFID) technology was used to wirelessly connect the book and computer, and Zigbee technology to wirelessly connect the computer and robot. RFID technology features low cost, intuitive operation, and contextual adaptability, which attracts much attention. It has been widely used in our daily life, as well as educational settings (e.g., Harumi, Yan, Yi, Min \& Kazuhiro, 2009; Kanda, Hirano, Eaton \& Ishiguro, 2003). Similarly, the Zigbee technology, which has been adopted as one of the communication standards, features low power consumption, low cost, high reliability, and multi-node support. It was used in this system to provide stable wireless signal transmission between the computer and robot. The Zigbee technology frees the robot from the cable connection that could constrain the robot's movements and motions.

In the past, learning with computers required users to have some basic computer skills such as keyboarding. This kind of implicit instrumental knowledge somehow restricts people's willingness to use a computer and in turn affects the effectiveness of computer-assisted learning (Fidaoui, Bahous \& Bacha, 2010; Lam \& Pennington, 1995). To help young students learn English with computers, it is essential to lower the 
barrier of operating the computer system. For this reason, we developed a user interface which is easy to use, and similar to the way we communicate with people in our daily life. The intuitive and friendly user interface will require young students to apply the least effort to get familiar with operating the system and enhance their motivation to learn English with the system (Marakas, Yi \& Johnson, 1998).

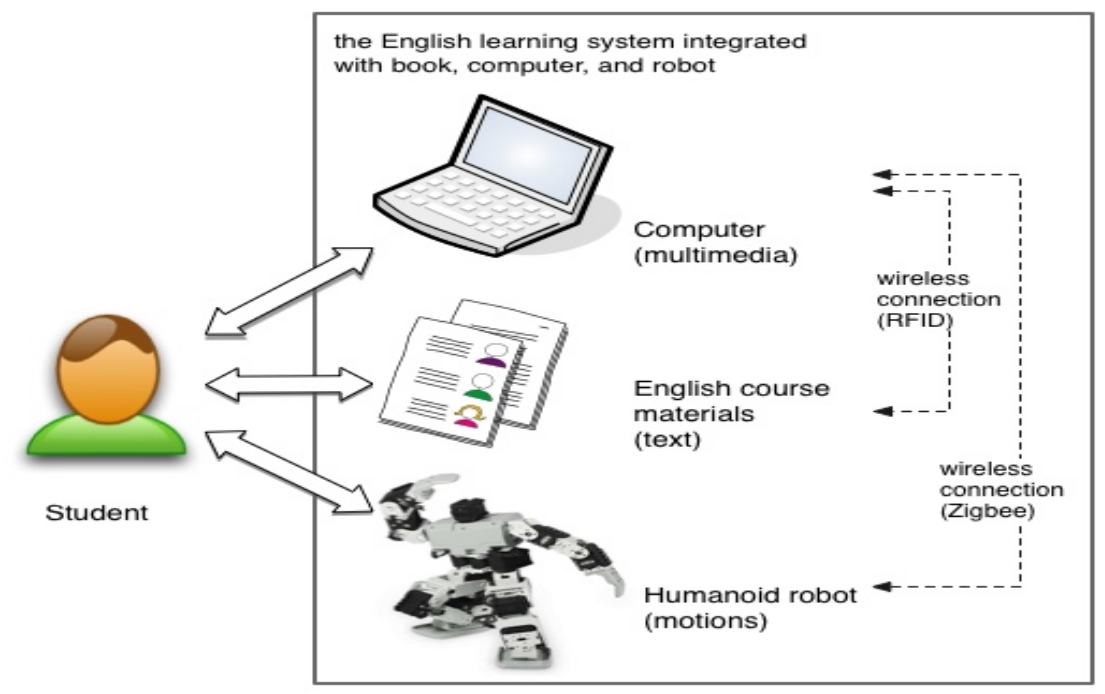

Figure 1: The framework of the integrated English learning system

In learning with the new system, when a learner has difficulties in understanding certain vocabulary (or sentence) in the book, he or she uses the RFID reader to point to the word (or sentence). The RFID reader detects RFID tags embedded in the book and transmits the object information to the computer. The computer then fetches the stored multimedia object associated with the RFID tag and displays the lexical information on the screen with pictoral information together with audio and video outputs. Meanwhile, the robot receives the request sent by the computer via the Zigbee signal and performs the corresponding motion to help the learner better perceive the meaning of the word (or sentence). All these processes are initiated by the learner during the learning activity. Figure 2 is a starting page for the system, introducing the hardware requirement, instructions for operation, and the icons used in the system along with the type of digital material they associated with.

\section{The design of learning activities}

Liu, Moore, Graham, and Lee (2000) in a review of computer technology used in language learning from 1990-2000 suggested positive effects of visual media in supporting vocabulary acquisition and learning comprehension. However, they also found that most of the studies addressed reading and writing skills, but only a few focused on listening and speaking skills. Based on the levels of English language representations (Berninger \& Richards, 2002) and the involvement of receptive and expressive skills (Warschauer, 1996), five learning activities were designed in the new system, including vocabulary, conversation read-along, conversation role play, singing and dancing, and cloze test. Details about each learning activity are described below. 


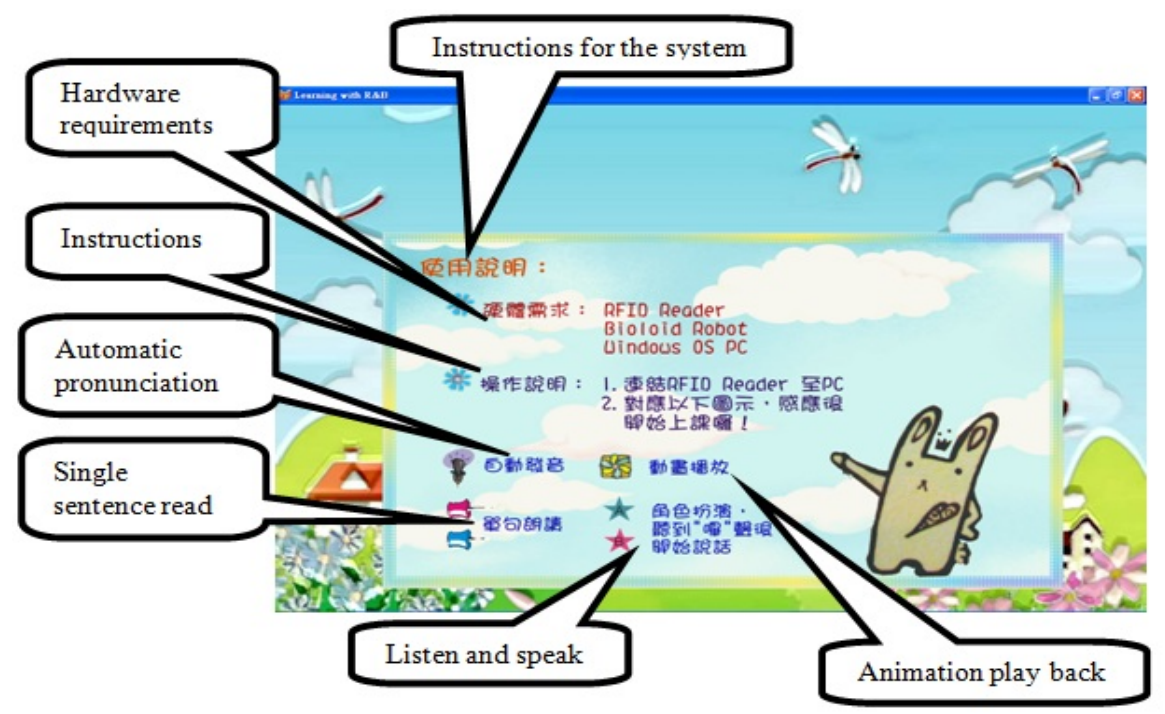

Figure 2: The starting page

\section{Vocabulary learning}

Learning vocabulary is an important aspect of language development because vocabulary is the building block for reading comprehension in a second language (Abraham, 2008; Tozcu \& Coady, 2004). Neri, Mich, Gerosa and Giuliani (2008) suggested that applying computer technology to provide students with correct pronunciation of vocabulary benefits their learning of a foreign language. Silverman and Hines (2009), similarly, suggested that multimedia-enhanced instruction had positive effects on the vocabulary learning for non-English-learners.

In this study, students learned vocabulary with textual, picture, and animation annotations. Students used the RFID reader to contact the pictorial icons to sense the embedded RFID tags. The computer fetched the associated multimedia information from the database and presented it to the learner. In this learning process, students did not have to use the keyboard, hence no keyboarding is necessary. Figure 3 is a snapshot of the activity of learning vocabulary.

\section{Conversation read-along}

Built upon the knowledge of vocabulary, a conversation was designed for students to practice how the words can be structured in a sentence and how they can be used in oral expressions. Students are allowed to read each sentence along with the computer as many times necessary. The computer plays the sentence with the audio effect and the robot performs the corresponding motion. This makes learning reading sentences more enjoyable and enriches learner's learning experience.

Being familiar with each single sentence, the learner can proceed to read the whole conversation along with the computer. The purpose for this design was to help students become familiar with the whole scenario the conversation was about. 


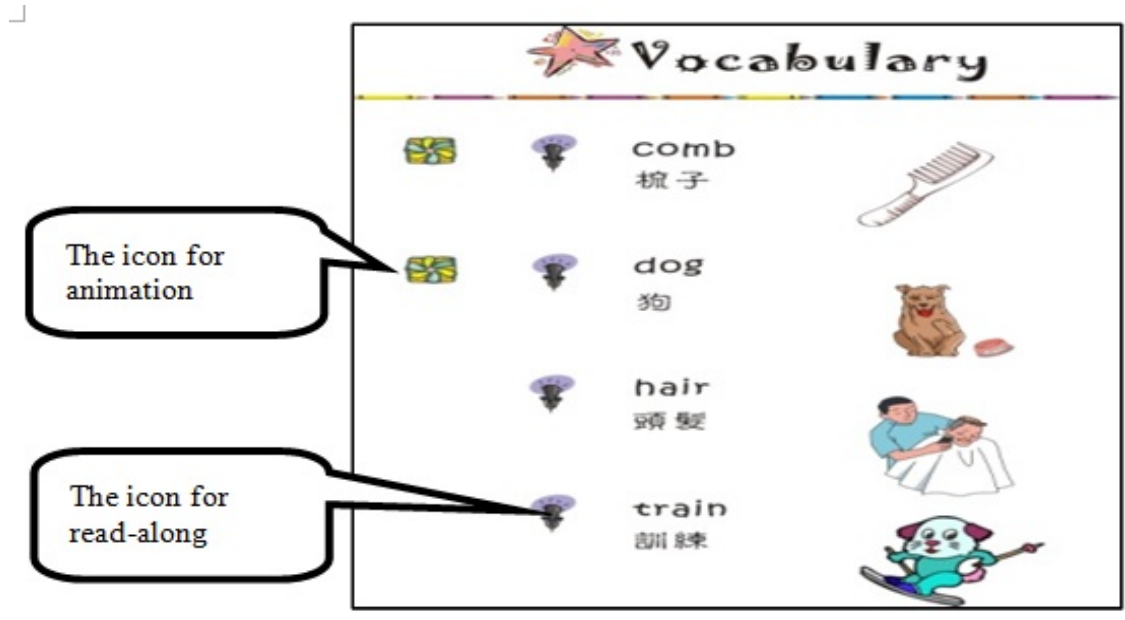

Figure 3: A snapshot of learning vocabulary

\section{Conversation role play}

To help learners obtain a concrete experience in oral English, the activity of conversation provided an interactive way of practising conversation. In a given scenario, students are allowed to play a role in the conversation, whereas the robot playing the other role. By using the microphone, students can "really" talk to the robot, and the robot will react to the student according to the conversation. This feature brings students a vivid experience of social interaction as it happens in our daily life. The robot in the conversation serves as a pedagogical social agent (Atkinson et al., 2005; Craig, Gholson \& Driscoll, 2002). Figure 4 is a snapshot of the conversation activity. Students can choose the activities of read-along or role play by contacting the corresponding icon using the RFID reader.

\section{Singing and dancing}

In addition to learning vocabulary, sentence, and the conversation, the function of singing and dancing was also provided. The purpose for singing and dancing was to enhance students' perception of words and sentences by incorporating relevant sensory-motor information (Berninger \& Richards, 2002) and a fun factor (Warschauer, 1998). By sensing the singing and dancing icon, the computer will play the song and the robot will perform dancing along the song. Two different singing and dancing modes were provided: sentence by sentence or the whole song. As shown in Figure 4, an icon was provided to students to perform singing and dancing.

\section{Cloze test}

The cloze test has long been used to test students' reading comprehension (e.g., August, Carlo, Dressler \& Snow, 2005; Jonz, 1990; Stahl, Jacobson, Davis \& Davis, 1989). A story was used as the content, with some verbs missing in the story. Verb words were made available in cards embedded with RFID tags. When filling in a verb, students attached the RFID reader to the desired card. There was no correct or wrong answer for the story, so students can make their own story by varying verbs in the sentences. The robot will perform the motion corresponding to the selected verb. After 
completing the whole story, the robot can perform a series of motions according to the content. Figure 5 is an example of learning reading with cloze test. After the learner contacted the selected verb with the RFID reader, the system will fill in the blank automatically on the screen.

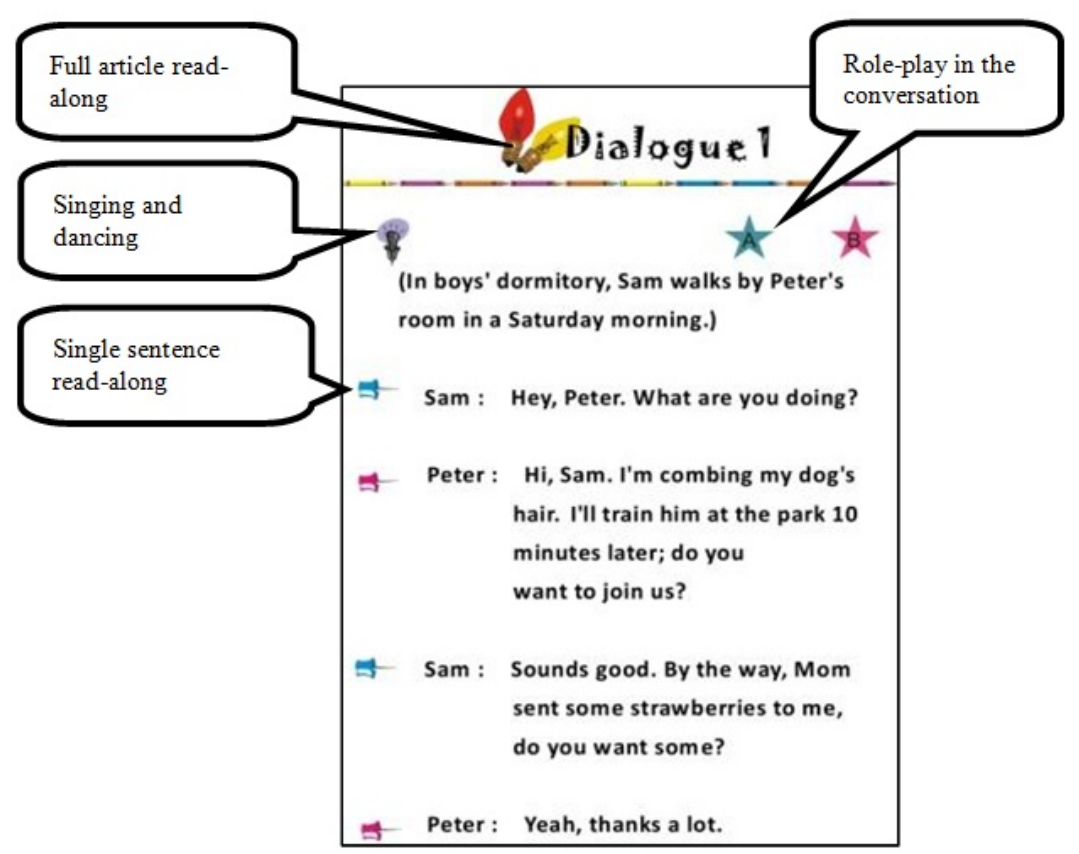

Figure 4: An example page of the conversation activity

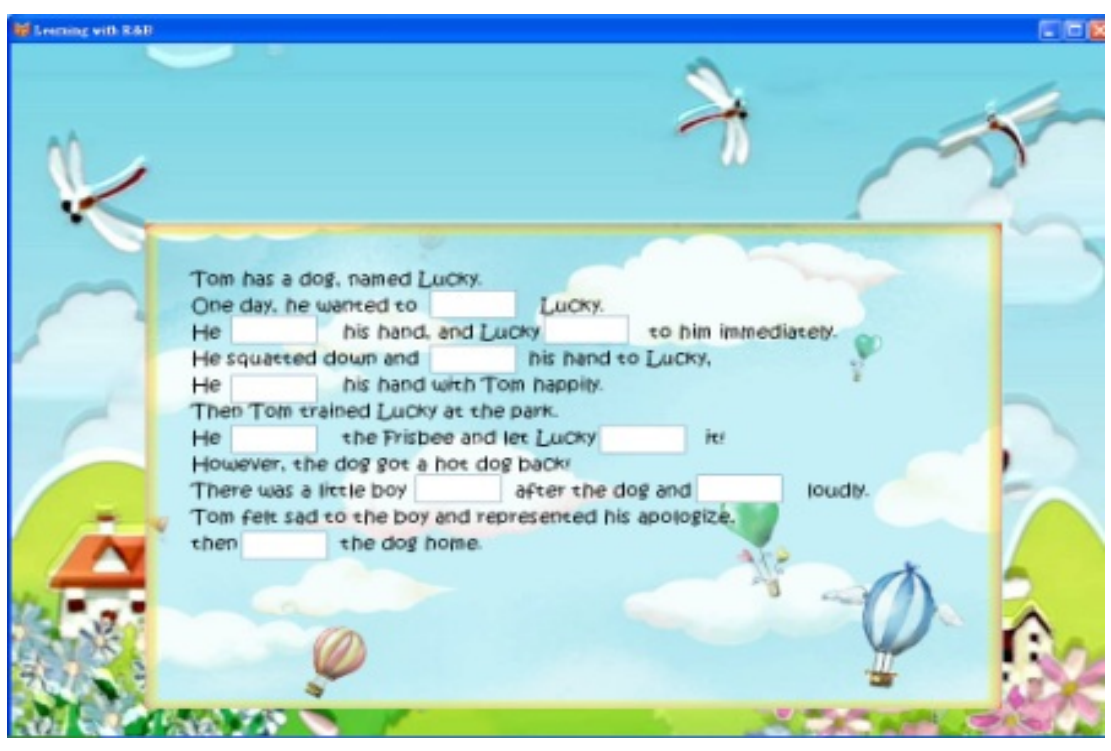

Figure 5: A snapshot of the cloze test 


\section{System evaluation}

An evaluation session was taken in spring, 2010, in a rural elementary school in southern Taiwan. Five fifth-graders (three boys and two girls, at the age of 10 to 11) were recruited. The total time of the evaluation session was about 80 minutes. The whole evaluation process was video recorded, to complement researchers' field observations and notes.

The evaluation procedure is described in Table 1. Students were first introduced the features and usage of the system - the book, computer and robot - with the RFID reader. The researchers then guided the students through all types of learning activities. Students took turns to have a test drive on the system. Students' reactions to and interactions with the system were captured. Figure 6 is a picture showing how students were learning English with the system.

Table 1: Procedures for evaluating the feasibility of the system

\begin{tabular}{|c|c|c|}
\hline Steps & Purpose and observation & $\begin{array}{l}\text { Time } \\
\text { (mins) }\end{array}$ \\
\hline 1 & $\begin{array}{l}\text { - Introduce students to the system and its features. } \\
\text { - Instruct students on how to use the system to learn English. }\end{array}$ & 15 \\
\hline 2 & $\begin{array}{l}\text { - Students engage in all types of learning activities } \\
\text { - Observe how the student learns English with the system in terms of the } \\
\text { joyfulness, engagement, and active participation. }\end{array}$ & 40 \\
\hline 3 & $\begin{array}{l}\text { - Interview with students about their learning experience and obtain } \\
\text { feedback about the feasibility of the system }\end{array}$ & 15 \\
\hline 4 & $\begin{array}{l}\text { Interview the teacher and principal and consult them about how to help } \\
\text { students learn better with the system, compare the system with others, } \\
\text { and consider possible improvements to the system. }\end{array}$ & 10 \\
\hline
\end{tabular}

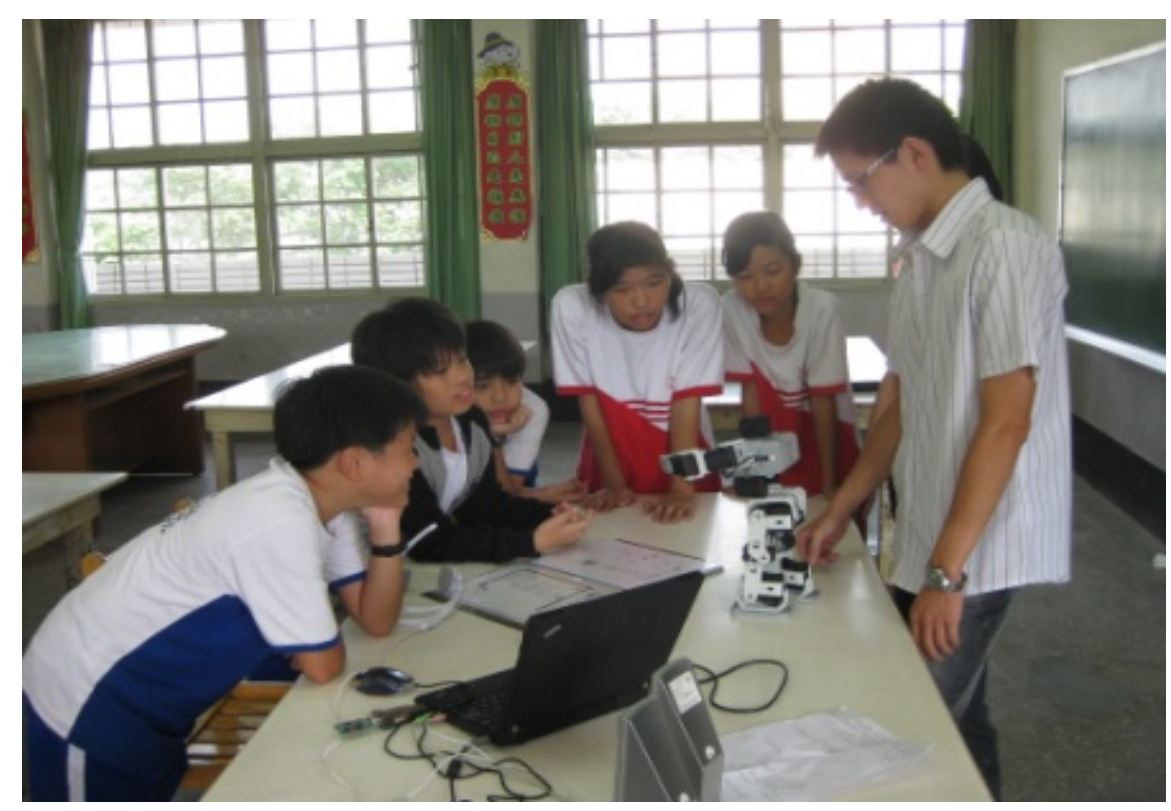

Figure 6: A scene on the evaluation of the system 
After all learning activities were completed, an interview was conducted, to understand their experience of learning with the new system, and also to obtain students' feedback on system designs and possible improvement to the system. The students' English teacher and the school Principal were interviewed to gain their insights about the difficulties most students encountered in formal English learning and how the system can be useful and be integrated into their English curriculum.

Data collected from video recording and interviews were then analysed. The results are reported in the next section.

\section{Results and discussions}

This section reports the results of data analyses from video recordings and interviews concerning the usability and feasibility of the integrated system in terms of system features, learning activities, and students' engagement.

\section{System features}

The proposed system is easy to use. The video recordings showed that shortly after the researcher demonstrated how to learn English with the system, all five students were able to operate the system by themselves, although they had no prior experience with using the proposed system. In the interview, three out of five students agreed that learning vocabulary with the computer and robot helped them understand new words. One student stated that "the new way of learning vocabularies is better [than conventional drill and practice] because the new system provides each word a corresponding picture and animation, which really helped me know the words." Similarly, four of the five students mentioned that they enjoyed having conversations with the robot because "the robot performed the motions." Students have a positive attitude toward using the system to learn English. Four students mentioned that the system can be used to facilitate the practice of vocabulary, pronunciation, and conversation after class because "we can learn the word and its pronunciation without typing the word into the computer or looking it up in the dictionary." This could be one of the reasons which motivated their learning with the system.

\section{Learning activities}

Practising conversation with the robot helped students become more confident in speaking English. Three students thought that a long-term practising of conversation with the robot could help them feel more confident in speaking English. Therefore, the use of robot may encourage students who are reluctant to speak English, to have conversations with the robot as a learning partner, and through this process students will build up confidence in their spoken English and communicating in English. This could be very helpful for students learning English in non-English-speaking countries. Though interacting with the robot was a novel experience to students, use of robot may have brought students a first-person experience of speaking English, as if communicating with a human companion.

\section{Students' engagement}

During the whole learning process, all five students were fully engaged in the learning activity and the interactions with the computer and robot. They took turns to use the system and actively participated in the learning exercises. It is evident that students 
were highly motivated and having fun while learning English with the proposed system. We concluded from the video recordings that learning English with this new system does bring students a positive learning experience. Students kept trying out new materials and were willing to take challenges which were beyond their current level. Such positive learning experiences may well sustain their future learning of English.

However, in the interview with the teacher, she mentioned that "learning with multimedia could be fascinating to a large number of students at the beginning, but the learning effect will fade away if there are no continuous updates to the material." Students may lose their interest in using the system if the content or the instructional strategy remains the same. Also, the cost could be an issue for adopting the proposed system into formal English classes. The Principal mentioned that "the cost of the learning system will influence parents' decision to adopt the system in learning English." Considering the cost, therefore, the scalability and compatibility of the learning system needs to be taken into account in designing and developing the system. In this present case, the content materials should be updatable, changeable, and replaceable, such that the computer, robot, and RFID facilities can be re-applied to other disciplines to keep the learning cost reasonable.

\section{Conclusion}

This study attempted to integrate the books, computer and robot to develop an English learning system, and to understand the usability and feasibility of the proposed system. Five learning activities were designed in the system, including vocabulary, conversation read-along, conversation role play, singing and dancing, and cloze test. In each learning activity, the computer provides pictorial representations and animations along with audio effects to students. Students interacted with the computer by an RFID reader to read the graphical icons or word cards embedded with RFID tags. The RFID technology applied in this study lowers the overhead in the interaction with the computer system.

Interacting with the robot brought students a context that mimics human-human interactions in real life. Use of the robot benefits students by giving a first-person learning experience through conversation, singing and dancing with the robot. Students felt comfortable in practising oral conversation with the robot. And during the learning process, they were getting more confident in their spoken English. The motions performed by the robot provided students a novel kind of knowledge representation which not only manifests the abstract meaning of some vocabularies but also captures their attention. However, the cost, stability, and the interface design of the system could be educators' concerns in adopting the robot in learning activities.

The field observations and interviews suggested that this system motivated elementary school students to learn English and engage them in learning activities. The students were positive towards the system and enjoyed learning with the proposed system. The design of the system provides a context that is highly interactive, surpassing conventional kinds of computer-assisted learning systems. However, this is only a preliminary work of integrating book, computer, and robot into one learning system and using it in a real learning practice. More work need to be done to advance this study to help us understand how the integrated system can be effective and useful in learning English. 
Some future research directions are recommended. First, an authoring tool is required to help learners to design or compose the animation effects and the robot's motions so as to deepen their understanding of the learning content through the design process. Second, a composing tool which allows students to upload their favourite English songs and to have the robot dance along with the new song would be very useful. Third, the current design of narration in vocabulary, single sentence read-along and full article read-along needs to be improved so that the speed of narration can be adjusted according to the user's needs. Fourth, the current system was developed on platform of a laptop computer. In the future, the system should be scalable and transplantable to mobile devices such as tablet computers or smart phones to make it portable and movable. Also, digital learning content should be accessable via the Internet (e.g., cloud servers), so that the learners can access those materials anytime, anywhere. Fifth, how do students interact with the three components in different learning scenarios and what difficulties do they face in using the integrated system? Last but not the least, the system should be applicable to different disciplines, such as maths and science. In this case, interdisciplinary cooperation will be essential, as a computer-assisted learning system cannot be successful without contributions from the appropriate domain experts.

\section{Acknowledgments}

This research was supported in part by the National Science Council, Taiwan under contract numbers NSC99-2511-S-110-004-MY3 and NSC99-2631-S-011-002.

\section{References}

Abraham, L. B. (2008). Computer-mediated glosses in second language reading comprehension and vocabulary learning: A meta-analysis. Computer Assisted Language Learning, 21(3), 199226. http:/ / dx.doi.org/10.1080/09588220802090246

Adams, J. A. (2009). Multiple robot/single human interaction: Effects on perceived workload. Behaviour \& Information Technology, 28(2),183-198. http: / / dx.doi.org/10.1080/01449290701288791

Akbulut, Y. (2007). Effects of multimedia annotations on incidental vocabulary learning and reading comprehension of advanced learners of English as a foreign language. Instructional Science, 35(6), 499-517. http:/ / dx.doi.org/10.1007/s11251-007-9016-7

Atkinson, R. K., Mayer, R. E. \& Merrill, M. M. (2005). Fostering social agency in multimedia learning: Examining the impact of an animated agent's voice. Contemporary Educational Psychology, 30(1), 117-139. http:/ / dx.doi.org/10.1016/j.cedpsych.2004.07.001

August, D., Carlo, M., Dressler, C. \& Snow, C. E. (2005). The critical role of vocabulary development for English language learners. Learning Disabilities Research E Practice, 20(1), 50 57. http: / / dx.doi.org/10.1111/j.1540-5826.2005.00120.x

Ayres, R. (2002). Learner attitudes towards the use of CALL. Computer Assisted Language Learning, 15(3), 241-249. http: / / dx.doi.org/10.1076/ call.15.3.241.8189

Bernard, M. L., Chaparro, B. S., Mills, M. M \& Halcomb, C. G. (2002). Examining children's reading performance and preference for different computer-displayed text. Behaviour $\mathcal{E}$ Information Technology, 21(2), 87-96. http: / / dx.doi.org/10.1080/01449290210146737

Berninger, V. W. (1994). Reading and writing acquisition: A developmental neuropsychological perspective. Madison, WI: W. C. Brown. Distributed by Perseus Books. 
Berninger, V. W. \& Richards, T. L. (2002). Brain literacy for educators and psychologists. New York, NY: Academic Press.

Billard, A. (2003). Robota: Clever toy and educational tool. Robotics and Autonomous Systems, 42(3-4), 259-269. http: / / dx.doi.org/10.1016/S0921-8890(02)00380-9

Birk. A., Poppinga. J. \& Pfingsthorn, M. (2009). Using different humanoid robots for science edutainment of secondary school pupils. In L. Iocchi et al. (Eds.), RoboCup 2008, LNAI 5399 (pp. 451-462). Berlin, Heidelberg: Springer-Verlag.

Brown, B. (2000). The artful use of groupware: An ethnographic study of how Lotus Notes is used in practice. Behaviour and Information Technology, 19(4), 263-273. http: / / dx.doi.org/10.1080/01449290050086372

Chang, C. K., Chan, T. W. \& Yang, J. C. (2007). Learning activity design on mobile learning device: Using ESL reading comprehension as example. Paper presented at the meeting of the 13th International Study Association on Teachers and Teaching (ISATT 2007). St. Catharines, Ontario, Canada. http: / / www.isatt.org/ISATT-papers/ISATTpapers/Chang_LearningActivityDesignonMobileLearningDevice.pdf

Chang, C. W., Lee, J. H., Wang, C. Y. \& Chen, G. D. (2010). Improving the authentic learning experience by integrating robots into the mixed reality environment. Computers $\mathcal{E}$ Education, 55(4), 1572-1578. http:/ / dx.doi.org/10.1016/j.compedu.2010.06.023

Chapelle, C. A. (2009). The potential of technology for language learning. In P. Hubbard (Ed.), Computer assisted language learning (Vol. I, pp. 134-169). New York, NY: Routledge.

Chen, C. M. \& Chung, C. J. (2008). Personalized mobile English vocabulary learning system based on item response theory and learning memory cycle. Computers $\mathcal{E}$ Education, 51(2), 624645. http:/ / dx.doi.org/10.1016/j.compedu.2007.06.011

Chen, N.-S., Teng, D. C.-E., Lee, C.-H. \& Kinshuk (2011). Augmenting paper-based reading activity with direct access to digital materials and scaffolded questioning. Computers $\mathcal{E}$ Education, 57(2), 1705-1715. http: / / dx.doi.org/10.1016/j.compedu.2011.03.013

Coller, B. D. \& Scott, M. J. (2009). Effectiveness of using a video game to teach a course in mechanical engineering. Computers \& Education, 53(3), 900-912. http: / / dx.doi.org/10.1016/j.compedu.2009.05.012

Coller, B. D. \& Shernoff, D. J. (2009). Video game-based education in mechanical engineering: A look at student engagement. International Journal of Engineering Education, 25(2), 308-317. http: / / www.ingentaconnect.com/content/intjee/ijee/2009/00000025/00000002 / art00013

Craig, S. D., Gholson, B. \& Driscoll, D. M. (2002). Animated pedagogical agents in multimedia educational environments: Effects of agent properties, picture features, and redundancy. Journal of Educational Psychology, 94(2), 428-434.

http: / / www.sciencedirect.com/science/article/ pii / S0022066302000363

Erikson, E. H. (1963). Childhood and society (2nd ed.), New York, NY: W. W. Norton.

Fidaoui, D., Bahous, R. \& Bacha, N. N. (2010). CALL in Lebanese elementary ESL writing classrooms. Computer Assisted Language Learning, 23(2), 151-168. http: / / dx.doi.org/10.1080/09588221003666248

Grauberg, W. (1997). The elements of foreign language learning. Bristol, PA: Multilingual Matters Ltd. 
Harumi, K., Yan, X., Yi, S., Min, K. \& Kazuhiro, O. (2009). A language learning system utilizing RFID technology for total physical response activities. Proceedings of 13th International Conference on Human-Computer Interaction (pp.119-128). San Diego, CA. http: / / dx.doi.org/10.1007/978-3-642-02583-9_14

He, H., Ogura, T., Satou, A. \& Hasegawa, O. (2007). Developmental word acquisition and grammar learning by humanoid robots through a self-organizing incremental neural network. IEEE Transactions on Systems, Man and Cybernetics, Part B: Cybernetics, 37(5), 13571372. http: / / dx.doi.org/10.1109/ TSMCB.2007.903447

Heerink, M., Kröse, B.,Wielinga, B. \& Evers, V. (2008). Enjoyment, intention to use and actual use of a conversational robot by elderly people. Proceedings of the $3 \mathrm{rd}$ ACM/IEEE International Conference on Human Robot Interaction (HRI'08), 113-120.

http:/ / dare.uva.nl/ document/117732

Jonz, J. (1990). Another turn in the conversation: What does cloze measure? TESOL Quarterly, 24(1), 61-83. http:/ / www.jstor.org/pss/3586852

Kanda, T., Hirano, T., Eaton, D. \& Ishiguro, H. (2003). Person identification and interaction of social robots by using wireless tags. Proceedings of IEEE/RSJ International Conference on Intelligent Robots and Systems (IROS 2003, pp. 1657-1664). Las Vegas, NV. http: / / dx.doi.org/10.1109/IROS.2003.1248882

Kebritchi, M. \& Hirumi, A. (2008). Examining the pedagogical foundations of modern educational computer games. Computers $\mathcal{E}$ Education, 51(4), 1729-1743. http:/ / dx.doi.org/10.1016/j.compedu.2008.05.004

Klassen, J. \& Milton, P. (1999). Enhancing English language skills using multimedia: tried and tested. Computer Assisted Language Learning, 12(4), 281-294. http: / / dx.doi.org/10.1076/ call.12.4.281.5706

Lam, F. S. \& Pennington, M. C. (1995). The computer vs. the pen: A comparative study of word processing in a Hong Kong secondary classroom. Computer Assisted Language Learning, 8(1), 75-92. http: / / dx.doi.org/ 10.1080/0958822950080106

Liou, H.-C. (2000). Assessing learner strategies using computers: New insights and limitations. Computer Assisted Language Learning, 13(1), 65-78. http:/ / dx.doi.org/10.1076/09588221(200002)13:1;1-K;FT065

Liu, M., Moore, Z., Graham, L. \& Lee, S. (2003). A look at the research on computer-based technology use in second language learning: A review of the literature from 1990-2000. Journal of Research on Technology in Education, 34(3), 250-273. http: / / business.highbeam.com/619/ article-1G1-90870031/ look-research-computerbasedtechnology-use-second-language

Liu, T.-Y. (2009). A context-aware ubiquitous learning environment for language listening and speaking. Journal of Computer Assisted Learning, 25(6), 515-527. http: / / dx.doi.org/10.1111/j.1365-2729.2009.00329.x

Liu T.-Y, Tan T.-H. \& Chu, Y.-L. (2007). 2D barcode and augmented reality supported English learning system. Paper presented at the 6th IEEE / ACIS International Conference on Computer and Information Science (ICIS 2007). Montreal, Quebec, Canada. http:/ / dx.doi.org/10.1109/ICIS.2007.1

Marakas, G. M., Yi, M. Y. \& Johnson, R. D. (1998). The multilevel and multifaceted character of computer self-efficacy: Toward clarification of the construct and an integrative framework for research. Information Systems Research, 9(2), 126-163. http: / / dx.doi.org/10.1287/ isre.9.2.126 
Mayer, R. E. (2001). Multimedia learning. New York, NY: Cambridge University Press.

Mayer, R. E. \& Moreno, R. (2003). Nine ways to reduce cognitive load in multimedia learning. Educational Psychologist, 38(1), 43-52. http:/ / dx.doi.org/10.1207/S15326985EP3801_6

Ministry of Education (2004). The guideline of downward extension of primary school English lesson to third graders. Taipei, Taiwan: Ministry of Education. [viewed 22 Mar 2010; in Chinese] http: / / teach.eje.edu.tw / 9CC / detail.php?Item=\&ID=3084

Mitnik, R., Recabarren, M., Nussbaum, M., \& Soto, A. (2009). Collaborative robotic instruction: A graph teaching experience, Computers $\mathcal{E}$ Education, 53(2), 330-342. http: / / dx.doi.org/10.1016/j.compedu.2009.02.010

Mitsoni, F. (2006). 'I get bored when we don't have the opportunity to say our opinion': Learning about teaching from students. Educational Review, 58(2), 159-170. http: / / dx.doi.org/10.1080/00131910600584041

Murphy, R. R. (2004). Human-robot interaction in rescue robotics. IEEE Transactions on Systems, Man and Cybernetics, Part C: Applications and reviews, 34(2), 138-153. http: / / dx.doi.org/10.1109/TSMCC.2004.826267

Neri, A., Mich, O., Gerosa, M. \& Giuliani, D. (2008). The effectiveness of computer assisted pronunciation training for foreign language learning by children. Computer Assisted Language Learning, 21(5), 393-408. http: / / dx.doi.org/10.1080/09588220802447651

Neville, D. O., Shelton, B. E. \& McInnis, B. (2009). Cybertext redux: using digital game-based learning to teach L2 vocabulary, reading, and culture. Computer Assisted Language Learning, 22(5), 409-424. http: / / dx.doi.org/10.1080/09588220903345168

Pierris, G. \& Lagoudakis, M. G.(2009). An interactive tool for designing complex robot motion patterns. Proceedings of 2009 IEEE International Conference on Robotics and Automation (ICRA 2009, pp. 4013-4018). Kobe, Japan. http:/ / dx.doi.org/10.1109/ ROBOT.2009.5152877

Power. C. (2005). Not the Queen's English. Newsweek, 7 March, 41-45. [verified 6 Jun 2011] http: / / www.newsweek.com/2005/03/06/ not-the-queen-s-english.html

Sakai, K. (2005). Language acquisition and brain development. Science, 310, 815-819. http: / / dx.doi.org/10.1126/ science.1113530

Samaras, P. \& Gismondi, S. (1998). Scaffolds in the field: Vygotskian interpretation in a teacher education program. Teaching and Teacher Education, 14(7), 715-733. http: / / dx.doi.org/10.1016/S0742-051X(98)00024-9

Shaalan, K. F. (2005). An intelligent computer assisted language learning system for Arabic learners. Computer Assisted Language Learning, 18(1), 81-109. http: / / dx.doi.org/10.1080/09588220500132399

Shin, D. H. (2009). An empirical investigation of a modified technology acceptance model of IPTV. Behaviour E Information Technology, 28(4), 361-372. http: / / dx.doi.org/10.1080/01449290701814232

Silverman, R. \& Hines, S. (2009). The effects of multimedia-enhanced instruction on the vocabulary of English-language learners and non-English-language learners in prekindergarten through second grade. Journal of Educational Psychology, 101(2), 305-314. http: / / dx.doi.org/10.1037/a0014217 
Stahl, S. A., Jacobson M. J., Davis, C. E. \& Davis, R. L. (1989). Prior knowledge and difficult vocabulary in the comprehension of unfamiliar text. Reading Research Quarterly, 24(1), 27-43. http: / / www.jstor.org/pss / 748009

Tozcu, A. C. \& Coady, J. (2004). Successful learning of frequent vocabulary through CALL also benefits reading comprehension and speed. Computer Assisted Language Learning, 17(5), 473495. http:/ / dx.doi.org/10.1080/0958822042000319674

Warschauer, M. (1996). Computer assisted language learning: An introduction. In S. Fotos (Ed.), Multimedia language teaching (pp. 3-20). Tokyo, Japan: Logos International.

Warschauer, M. \& Healey, D. (1998). Computers and language learning: An overview. Language Teaching, 31(2), 57-71. http: / / dx.doi.org/10.1017/S0261444800012970

Wei, C. W., Hung, I. C., Lee, L. \& Chen, N. S. (2011). A joyful classroom learning system with robot learning companion for children to learn mathematics multiplication. The Turkish Online Journal of Educational Technology, 10(2), 11-23. http: / / www.tojet.net/articles/1022.pdf

You, Z. J., Shen, C. Y., Chang, C. W., Liu, B. J. \& Chen, G. D. (2006). A robot as a teaching assistant in an English class. Proceedings of the 6th IEEE International Conference on Advanced Learning Technologies (ICALT 2006, pp. 87-91). Kerkrade, Netherlands. http: / / doi.ieeecomputersociety.org/10.1109/ICALT.2006.31

Zhang, Y., Kinshuk, Jormannainen, I. \& Sutinen, E. (2008). An implementation of the agency architecture in educational robotics. Proceedings of the 8th IEEE International Conference on Advanced Learning Technologies (ICALT 2008, pp. 194-198). Santander, Cantabria, Spain. http: / / dx.doi.org/10.1109/ ICALT.2008.13

Authors: Dr Nian-Shing Chen, Distinguished Professor

Department of Information Management, National Sun Yat-sen University, Taiwan. Email: nschen@mis.nsysu.edu.tw Web: http: / / www.nschen.idv.tw

Benazir Quadir and Daniel C. Teng

Department of Information Management, National Sun Yat-sen University, Taiwan

Please cite as: Chen, N.-S., Quadir, B. \& Teng, D. C. (2011). Integrating book, digital content and robot for enhancing elementary school students' learning of English. Australasian Journal of Educational Technology, 27(3), 546-561.

http: / / www.ascilite.org.au/ajet/ajet27/ chen.html 